\title{
The Role and Contributions of Development NGOs to Development Cooperation: What Do We Know?
}

\author{
Nicola Banks
}

\begin{abstract}
31.1 INTRODUCTION
A long and rich history of academic scholarship on development nongovernmental organisations (NGOs) reveals much about their shape and strategy, their diverse priorities and modalities, and their operations and impact, among other things. One consistent question that has been asked in NGO research across the past three decades is whether and how NGOs can live up to their civil society functions alongside their successes in service delivery. Whereas one section of academic literature applauds NGOs for their impact across a number of diverse sectors and in diverse contexts (see the systematic review of Brass et al. [2018]), another body of literature takes a much more critical stance in asking whether this is enough, given the transformative ideologies and principles and the pursuit of social justice that underpin their motivations (see Banks et al. 2015). An increasingly managerial-driven aid system has fostered an increasingly professionalised cadre of development NGOs internationally, pulling them away from these more political roots and roles.

Although we know a lot qualitatively about the roles and contributions of development NGOs from existing literature, we know less quantitatively about their overall contribution to development cooperation. This is a problem rooted in the methodological approach that most academic literature takes. Nationally and internationally, data is not compiled in ways that can give us
\end{abstract}

\footnotetext{
N. Banks $(\varangle)$

University of Manchester, Manchester, UK

e-mail: Nicola.banks@manchester.ac.uk

(C) The Author(s) 2021 
a complete picture of the contributions of development NGOs in a donor country's overall foreign aid efforts, or of their holistic contributions in the countries where they operate. Research has a tendency to be based on small samples of (typically the largest) NGOs, within one country or internationally. Within such an approach, we lack knowledge on diversity and scale within the sector. A stronger methodological approach that seeks a sector-wide understanding of development NGOs within any given context would not only allow us to measure the added value of development NGOs to foreign aid, but would also allow us to explore their integration within the broader system of development cooperation. One key example here would be to explore the ways in which donor funding shapes and influences NGO sectors to prove or disprove common assumptions around NGO dependence on donor funding and the challenges that accompany this.

We seek to make advances in these new directions here, drawing upon recent research to extend our knowledge of the contributions of development NGOs to foreign aid efforts, and the implications that we can draw from this regarding their roles and relationships with development cooperation. We also explore the innovative ways in which the Dutch government has tried to respond to the challenges facing NGOs in the aid chain in its radical new policy for funding the political roles of NGOs, Dialogue and Dissent. This is an important precedent for a major donor to begin unpicking the managerialist ideology that underpins civil society funding. This policy is rooted in academic evidence and critiques of the sector, highlighting an important message for NGO researchers to maintain a radical stance rather than embrace the technical language and priorities of donors. This is a trend highlighted by Marberg et al. (2019) that risks buying into and prolonging the principles and ideologies held up by neoliberal regimes.

We first seek to define and summarise what we know about development NGOs. This focusses particularly on long-standing criticisms (Hulme and Edwards 1997) that highlight an increasingly professionalised but "watereddown" sector when it comes to generating and pursuing transformative social and political change. It also highlights limitations to our knowledge because of a lack of systematically compiled and analysed data on development NGOs within donor countries. The following two sections then advance our existing knowledge by looking at new innovations in policy and research. First, we explore recent innovations in Dutch foreign policy that have confronted these challenges, exploring their new policy that seeks to promote NGOs as vehicles of direct political action. We then look at new research in the UK and Canada that has taken a much broader methodological approach to understanding development NGO sectors. Section 31.5 then concludes with how these new studies have added to our understanding of the roles of development NGOs in development cooperation.

We find that although there is strong evidence of increased development cooperation from NGOs as key development actors, long-standing critiques of the extent to which they have been able to expand their political roles 
alongside this means that the NGO sector can be seen as a good example of "contested cooperation". Although measuring their roles and operations against progress made towards each of the Sustainable Development Goals (SDGs) is beyond the scope of this chapter, we finish with some reflections for what this means for SDG 17 (Partnerships for the goals).

These case studies - the Netherlands, the UK, and Canada - give us diverse insights into NGO sectors (and their influences) across different contexts. Their selection has been predominantly due to availability. With regard to policy, this is the first attempt to promote the political roles of NGOs by a Development Assistance Committee (DAC) donor (DAC 2018); with regard to research, these are the only attempts the author is aware of in terms of systematically analysing development NGO sectors in Northern contexts.

Before we move on, it is also important to define what is meant by "development NGOs". This is not as easy as it may seem. Academic literature has in fact struggled to "define" development NGOs, given the breadth and diversity within and among them (see Vakil 1997). There is great heterogeneity in development NGOs across the Global North and South for example, or in terms of their size and spheres of operation, and in their motivations, among other things. Yet, despite this, there has been increasing recognition of development NGOs as a "sector" (Marburg et al. 2016), and by this, we mean those NGOs working in the field of international development who pursue "development alternatives" that offer more people-centred and grassroots approaches to development than those pursued by the state and market.

\subsection{What Do We Know About Development NGOs?}

An increasing proliferation of research on development NGOs has accompanied the "meteoric" rise of NGOs in international development over the past three decades (Brass et al. 2018). This research highlights the dramatic transformation of NGOs as they have become increasingly prominent actors in development: They are bigger, more numerous, and more sophisticated, receiving larger sums of development finance than ever before (Banks et al. 2015). Funding channelled to, or through, development NGOs by DAC donor governments has increased from $\$ 17.4$ billion in 2010 to $\$ 19.8$ billion in 2016 (DAC 2018).

This makes them rightly deserving of an increasing research profile. Yetand perhaps this may seem a controversial statement-despite this expanding empirical knowledge base, research has stayed within a relatively confined range of themes and theories, development contexts, and "types" of development NGOs. There remains, for example, a distinctive bias of research and knowledge production towards the biggest NGOs (Banks and Brockington 2018) and towards more populous or politically important countries (Brass et al. 2018). Another hugely significant blind spot when it comes to NGO research is understanding how particular NGO "sectors" are structured and operate-those based in a particular country or working on a particular 
theme, for example. This means that while we know a lot about development NGOs, we know a lot less about their overall contributions to development cooperation. Rarely are they discussed in the questions or the measurement and analyses of "foreign aid", or development cooperation more broadly, for example. Many underlying assumptions or narratives of the sector (e.g. as being the pawn of donor governments, overly dependent on their funding and priorities) would perhaps indicate that their contributions are not significant enough to include in such discussions. But these assumptions are not grounded in research or evidence. In fact, the problem has been that research has not been systematic enough to measure this. ${ }^{2}$

Here we look at what we know about development NGOs, theoretically and empirically. A systematic review of 35 years of scholarship on NGOs and international development (Brass et al. 2018) is critical reading for anyone interested in a broader discussion of this than we can do justice to. It is certainly not something worth duplicating here. One research gap that becomes prominent when looking at the six overarching research questions that categorise this wealth of development NGOs is exactly the one stated above. Looking from a more sector-wide perspective, how do the contributions of development NGOs "add up"? What do they contribute to development cooperation more generally? Until recently, these two questions have been unanswerable because of methodological issues. No pre-existing databases systematically collect NGO data on incomes and expenditures at the country level, let alone globally. It is no surprise then that research on NGOs has been primarily qualitative, rather than quantitative (Brass et al. 2018). But this means our awareness of NGOs as core development stakeholders making significant contributions to development cooperation is vastly limited.

Let us first review this pre-existing literature before moving on to look at two recent studies that have made the methodological advances necessary to start understanding the size, structure, and mechanics of development NGO sectors in the UK (Banks and Brockington 2018) and Canada (Davis 2019).

Brass et al. (2018) find that the literature on NGOs is framed around six key issues regarding (i) the nature of NGOs, (ii) their emergence and development, (iii) how they conduct their work, (iv) their impacts, (v) how they relate to other actors, and (vi) how they contribute to the (re)production of cultural dynamics and power asymmetries through their operations. The systematic nature of their work is also revealing of the bias within existing research in terms of the countries (focussing on the most populated or most politically salient countries) and sectors (focussing primarily on governance and health sectors) that it overwhelmingly focusses on, and in terms of its authorship, with Northern academics creating most of the published knowledge (Brass et al. 2018). A lack of voices from the Global South in NGO research is also highlighted by Kareithi and Lund's (2012) review. Banks and Brockington (2018) reveal one further important bias-that of a clear preference towards the largest international NGOs in case study methodologies, which, as Brass et al. highlight, dominate 54 per cent of academic papers on 
NGOs. We know little about whether these largest NGOs are representative of the many more development NGOs operating across the Global North and South, and as Brass et al. (2018) highlight, there is often no clear rationale laid out for choosing particular cases; in many instances, it is because of practitioner involvement with them.

One recurring concern throughout the research on NGOs is whetherand to what extent-NGOs are able to live up to their perceived comparative advantages and their promise of being genuine development alternatives, given the context of the hierarchical aid chains they are situated within. The work of David Hulme and Michael Edwards (1997) is seminal here. Their early work argued that while NGOs rose to prominence and "favour" for the roles they could play in strengthening good governance agendas and pursuing more people-centred approaches to development to fill in service delivery gaps, in fact many of these justifications were based on ideological grounds rather than on evidence. They highlighted the closeness of NGOs to the donors that funded them, asking whether this dependence undermined the strengths that justified their roles in the first place.

Eighteen years later, with the original authors, I found that research on NGOs across that period largely pointed to very similar conclusions. Despite significant growth and changes in the NGO landscape internationally, the ability of NGOs to meet their long-term transformative goals remains undermined by their weak roots in civil society and by a rising tide of technocracy and professionalisation that has swept through the world of foreign aid (Banks et al. 2015).

A critique of whether the modus operandi of NGOs enables them to pursue social justice as well as to meet the service delivery needs of disadvantaged groups is both widespread in the literature and consistent over time (Atia and Herrold 2018; Banks et al. 2015; Mitlin et al. 2007; Suarez and Gugerty 2016). The Buthe et al. (2012) study of 40 US development NGOs is an interesting addition to this literature because it analyses how development NGOs allocate their privately financed resources across the countries they operate within. Taking away the influence of donors from the analysis still reveals remarkably similar findings: A humanitarian discourse rooted in service provision based on objective need is the primary driver of how these NGOs allocate their privately sourced finances globally. There is only weak support in their sample that a stronger "development" discourse that seeks to tackle the deeper roots of poverty and to secure longer-term transformation influences their allocation (Buthe et al. 2012).

Perhaps a rather stark warning to researchers of NGOs comes from Marberg et al. (2019), who use topic-modelling to explore the language used by academic research into NGOs across the 1990-2010 period. This shows a clear trend of researchers beginning to take on the buzzwords used by donors and displays a clear dilution of the original principles identified in Drabek's (1987) original call to action for NGOs. Research in the early 1990s could be categorised along the lines of establishing purpose, doing good, and change. 
But this moved on to focus on effectiveness and accountability in the late 1990s, management and globalisation into the early to mid-2000s, education and being "more like businesses" in the late 2000s, and then turned to the language of strategy and regulation in 2010. They highlight that NGO researchers themselves also point to an increasing inclination towards professionalisation, warning that this should not come at the cost of upholding a critical stance on the language that maintains the governance system within neoliberal systems: keep contesting the system or adopt the language and uphold it (Marberg et al. 2019).

Against this rather sceptical theorising of NGOs in existing research, does it come as a surprise to also find that, on the whole, research also assesses the outcomes of NGO activities and interventions as having favourable effects, as the Brass et al. (2018) review also highlights? These things are not necessarily irreconcilable. Hulme and Edward's original criticism was not that NGOs do not have impact, but that positive impact in terms of measurable outputs such as service delivery or infrastructure provision does not equate to social justice. In this, too, we can argue that the focus of the SDGs themselves "fits in" to a measurement of NGO effectiveness in terms of benchmarking their progress towards the many targets and indicators nestled within the 17 goals. ${ }^{3}$ With the exception of SDG 17 on partnerships (which is discussed in the conclusions), there is little scope for assessing what the unique value-added role of NGOs (versus other actors) is in their contribution to meeting the goals. This is not something amenable to the measurable targets and indicators upon which goal-setting depends. What development NGOs contribute to the SDGs may be measurable in terms of outputs and indicators, but not how they do it, and it is this issue of process that is the heart of academic debate and the interest surrounding it.

If we prioritise the processes through which NGOs operate and the longerterm outcomes of social and political transformation that they aim for through these, then we are assessing a different kind of impact. Academic criticisms of development NGOs do not seek to demerit their contributions and successes in service delivery, but to highlight the fact that their operational modalities do not necessarily reconfigure the relationships between the state, the market, and civil society - as originally intended - in ways that lead to more pro-poor development. NGOs have to negotiate difficult accountabilities on two sides that pull them away from this more transformative role and from the grassroots populations that they are meant to represent. This includes the donors that fund them and the ways in which a managerial, project-based, and resultsfocussed aid system has led to increasingly professionalised organisations that are far-removed from the communities they represent and the modes of operation necessary to pursue incremental-but transformative-development. In Ghana and Indonesia, Kamstra and Schulpen (2015), for example, highlight the managerial forces through which donor funding leads to the homogenisation of NGOs; this is in stark contrast to the importance they attach to tailor-made approaches and the complexities of local contextual factors. 
At the same time, organisational survival also means negotiating and fitting in with government regulations that dictate whether and how NGOs operate. Across the Global South, there are many harsh examples of shrinking civil society space, creating complex challenges to NGO activities (Dupuy et al. 2016). Where governments equate civil society (often viewed synonymously with NGOs) with political opposition, creating regulations to dampen or repress it is widespread. The collapse of highly politicised NGOs working in areas of democracy promotion and politics is often a harsh warning to other NGOs seeking to stray into more democratic arenas (Ulvila and Hossain 2002). Instead, NGOs interested in organisational survival must persuade the state that they are non-political-a process that is incompatible with trying to reconfigure state-civil society relationships in order to advance the interests of marginalised social groups (Dicklitch and Lwanga 2003). Together, these influences-both from donor governments and governments in countries of operation-vastly restrict the ability of NGOs to seek more radical, political action and change. Yet, there are bright glimmers of hope due to one recent advancement. We see in the following section how one major donorthe Dutch government-has drawn upon this academic literature to design a radical new policy for funding the political roles of NGOs. This takes into account these major constraints on the ability of NGOs to act politically and sets important precedents in terms of focus and flexible funding arrangements.

\subsection{INNOVATION AND INFLUENCE in Donor Strategies for Civil Society}

As the previous section has illustrated, the aid chain raises multiple tensions and pressures that have constrained the ability of NGOs to work more politically towards goals of social justice and transformation. NGOs have become increasingly professionalised, and project-based approaches have dominated. This managerial approach has come at the direct cost of their transformative abilities (Yanguas 2018). These theoretical constructs and the empirical analyses that have pursued and affirmed them have a tendency to see donors like-for-like. There has been little academic research that looks at different donor approaches to civil society funding and whether and how differences in processes and procedures may influence these processes of professionalisation and the dilution of transformative principles that have accompanied these. This leads Kamstra and Schulpen (2015) to argue that future research should differentiate between different types of donors, recognising that there may be vast differences in flexibility and focus here.

One recent example is an innovative and radical new strategy for civil society funding by the Dutch government called Dialogue and Dissent: Supporting Civil Society's Political Role. They have directly sought to address the limited scope for political action for NGOs, drawing on diverse academic evidence in its rationale for, and design of, the policy. Through this, the Dutch Ministry of Foreign Affairs is dedicating one-quarter of its civil society funding (totalling 
close to $€ 1$ billion over the period 2016-2021) to political activities seeking to expand civil society through its flagship policy (Ministry of Foreign Affairs of the Netherlands 2017). Twenty-five Strategic Partnerships (of Dutch NGOs or Dutch NGO consortia and their global networks of Southern NGO and community-based organisation partners) have been funded to directly tackle lobbying and advocacy activities in low- and lower-middle-income countries around the world in partnership with local Dutch Embassies, offering new scope for NGOs to work on the more transformative ideologies in which they are rooted.

These Strategic Partnerships represent a strong shift from a managerial to a social transformative approach to funding development NGOs, recognising that development as broader transformation cannot be fostered through discrete and disparate projects or through the hierarchical relationships that have characterised the aid chain to date. The new policy explicitly recognises the original founding strengths of NGOs in its priorities, reconceptualising development as an indigenous process of changing power relations that must be locally owned to be effective and sustainable (Van Wessel et al. 2017). Consequently, funding must be spent on efforts that promote lobbying and advocacy, or on capacity-building and networking activities that fulfil explicitly political roles.

Within this new approach, there has been a complete shift in how the roles and value-added of international NGOs are conceptualised in the aid chain. Dutch NGOs are no longer the main vehicle in pursuing transformative change globally. Their roles are legitimated by the value they can add to local civil society organisation (CSO) partners in strengthening their capacity to pursue lobbying and advocacy work via training, resources, capacity-building, and network-building, among other things. This represents a movement towards the "bridge-building" role that Banks et al. (2015) advocate if NGOs are to get more serious about pursuing longer-term transformative and more inclusive development. Early evaluations of the Dialogue and Dissent policy highlight that Dutch NGOs and local civil society partners globally have applauded these changes, embracing the partnership approach, the more flexible funding and monitoring regime, and the fact it has opened up new possibilities in programming and action (Van Wessel et al. 2017).

At a 2019 stakeholder workshop I attended, the policy was described as "an island in a sea of managerial-driven international cooperation" by one civil society delegate. Likewise, the policy has been highlighted by the DAC (2018) as an "innovative and bold shift for the Netherlands" that is significant due to the precedents that it sets for other donors. ${ }^{4}$ Two are of particular significance. One highlights the returns to a shift from a managerial to a social transformative approach to development cooperation that recognises poverty is a political, rather than a technical, problem, and requires bold political approaches to tackle it - and more flexible regulations and monitoring requirements that enable this. The second highlights the possibilities of and returns to a new form of development cooperation that brings together bilateral donors, 
international NGOs, and local civil society in partnerships, rather than the strict hierarchical relationships that have characterised the aid chain to date. The Dutch Ministry of Foreign Affairs is no longer simply a funder of development projects, but a key ally and development partner in the 25 Strategic Partnerships, facilitating and protecting NGOs and their local partners in a context of shrinking civil society space globally. NGOs see added value in this partnership in the capacity of the ministry (via local embassies globally) to open doors, act as an ally for partners, assert greater leverage in their lobby and advocacy activities, and its ability to protect NGOs and their partners in difficult working environments (Van Wessel et al. 2017).

Flexibility is key to meeting the transformative goals of these Strategic Partnerships. Dialogue and Dissent provides space and flexibility that allows the partnerships to make their own choices and advance their own objectives without having to design programmes along donor priorities or to report heavily throughout the design, implementation, and evaluation phases. It offers opportunities for partnerships to negotiate adjustments in interventions and budgets in response to new opportunities, challenges, or learnings (CARE Netherlands 2017). Relationships with the ministry as donor have shifted away from one of reporting to, to one of collaborating with.

While offering an exciting potential for development NGOs, it is also important to highlight that structural changes like this to the funding system are also a huge challenge and trigger for change for development NGOs (Schulpen et al. 2018). As well as opening new opportunities, this can raise new challenges. Discussions at the 2019 workshop I attended, for example, suggested that NGOs had struggled to pass on this flexibility in funding that is afforded to them under Strategic Partnerships to local NGO partners in the Global South. This makes the approach taken throughout this first phase of the policy-including regular multi-stakeholder interactions and dialogue and a significant investment into academic research projects "testing" the assumptions upon which the policy is founded-critical to learning from the lessons experienced so that they can be addressed moving forwards.

A monitoring tool designed in collaboration with the Strategic Partnerships has replaced rigid management tools such as Results Based Frameworks and Logical Framework Analyses. This unique "outcome-harvesting" approach to monitoring outcomes explores the impact the partnerships have had along a number of benchmarks, but in much more fluid ways that recognise which social and political changes are harder to capture in rigid monitoring and evaluation frameworks. Evaluation looks for outcomes that represent political change: new policies or laws created or implemented; the number of spaces created for seeking political change; the number of people trained in capacitybuilding for political participation; the number of instances of participation in local governance processes; the number of CSOs with increased lobbying and advocacy capacities; the number of institutions strengthened to become more responsive, among other things. These are verified externally and uploaded to become publicly accessible through the global aid reporting standard of the 
International Aid Transparency Initiative d-portal database, making the data both accessible and comparable.

Just one example: An external mid-term review of CARE Netherlands' Every Voice Counts programme highlights that it "has, in a relatively short period of time [...] managed to advance the promotion of inclusive and effective governance processes" (CARE Netherlands 2017, p. viii). That this is a programme seeking inclusive and pro-poor development in fragile and postconflict settings in which certain segments of society are structurally excluded from local, district, and national governance processes makes this even more striking. With this Strategic Partnership, the Dialogue and Dissent programme has enabled CARE to design and implement a political programme of action and broad networks that would not traditionally fit into donor requirements and frameworks (Lori Cajegas, personal communication, 2019).

To recap, this policy innovation displays two important shifts for donorNGO relationships in ways that are critical to the heart of long-standing academic critiques of development NGOs. One is a shift away from a technical and managerial approach to funding development NGOs to a social transformative approach. The second is a shift away from seeing NGOs as service delivery organisations to reconceptualising their role as bridge-builders whose key roles are to strengthen and connect locally rooted CSOs with nationaland local-level institutions and processes in their countries of operation. These two shifts are imperative if NGOs are to fulfil their potential in pursuing longer-term transformation and social justice.

\subsection{What Does a Sectoral Approach to Development NGOs Contribute to OUR Understanding?}

Above we highlighted a lack of systematic analysis of NGO sectors as a major constraint on our understanding of development NGOs. Lacking this more representative sector-wide understanding of how NGO sectors look or perform in any given country (or thematic sector) makes it impossible to accurately explore their contributions to development cooperation. Although research on development NGOs alludes to development NGOs as a collective-as a group thought of for their cumulative consequences and influences-it has tended to focus on individual or small collectives of NGOs and to concentrate on the largest (Banks and Brockington 2018). ${ }^{5}$ This means we know much less about the size, composition, and contributions of diverse sectors globally, or about how they are financed, structured, and operate. Here, in fact, we know surprisingly little.

Those funding, working in, or researching the sector would no doubt all agree that NGOs play an important, if not sometimes contentious, role. But, until recently, there has been no data systematically compiled that allows us to measure accurately how major or minor they are as actors. Donors 
may now be requiring government-funded projects to report to global standards databases such as the International Aid Transparency Initiative d-portal database, but NGOs receive income from multiple sources that do not have to be reported through these channels. This is also a critical issue for policy. How can civil society policies be evidence-based if decision-makers lack stronger empirical knowledge bases? New methodological advances made recently in NGO research are beginning to answer these questions.

Two recent studies in the UK (Banks and Brockington 2018) and Canada (Davis 2019) offer revealing sector-wide insights. Through creating databases of UK-based and Canadian development NGOs and measuring their incomes, expenditures, and sources of income, both studies highlight that the financial contribution of NGOs to international development is hugely significant. In 2015, British development NGOs spent the equivalent of 55 per cent of all UK official development assistance (ODA) for that year (Banks and Brockington 2018). In Canada, this figure increases to around 60 per cent; 14 ODA-eligible countries receive more aid from Canadian NGOs than they do from Canadian ODA (Davis 2019). These new databases reveal that NGOs are far from being secondary or minor development actors. Increasing levels of funding from multiple sources (including the general public as the biggest financial supporter) have elevated their contributions to such an extent that they are major players globally. That development NGO sectors and their contributions have been unquantifiable until this new methodological approach means that their roles in, and contributions to, domestic foreign aid efforts have been underestimated.

Such a systematic approach can also enable important insights beyond these headline figures, allowing new analyses to shed light on theories or widespread assumptions about the sector. As those familiar with NGO research are aware, NGO positioning between donors and their local Southern partners leads to questions around their autonomy, accountability, and grassroots orientation. As Sect. 31.2 details, questions over whether NGOs are "too close for comfort" have been a long-standing concern of academic research (Hulme and Edwards 1997). In fact, it was this assumption and widespread criticism in Canada - that non-governmental "aid" was not "non"-governmental at all because of a dependence on government funding - that inspired Davis (2019) to compile his database to test this. This dominant narrative is unjustified, he finds, with only 13 per cent of Canadian NGOs receiving any form of government funding. These insights are critical to working towards a more nuanced narrative that reflects the complex realities of domestic NGO sectors. It also allows us to identify those organisations that do rely somewhat (or heavily) upon government funding in order to explore in more depth whether and how this influences their vision, direction, and activities.

Likewise Banks and Brockington's (2018) research reveals that the British public have been by far the biggest supporters of Britain's development NGO sector, contributing 40 per cent of the sector's income across the 2009-2014 


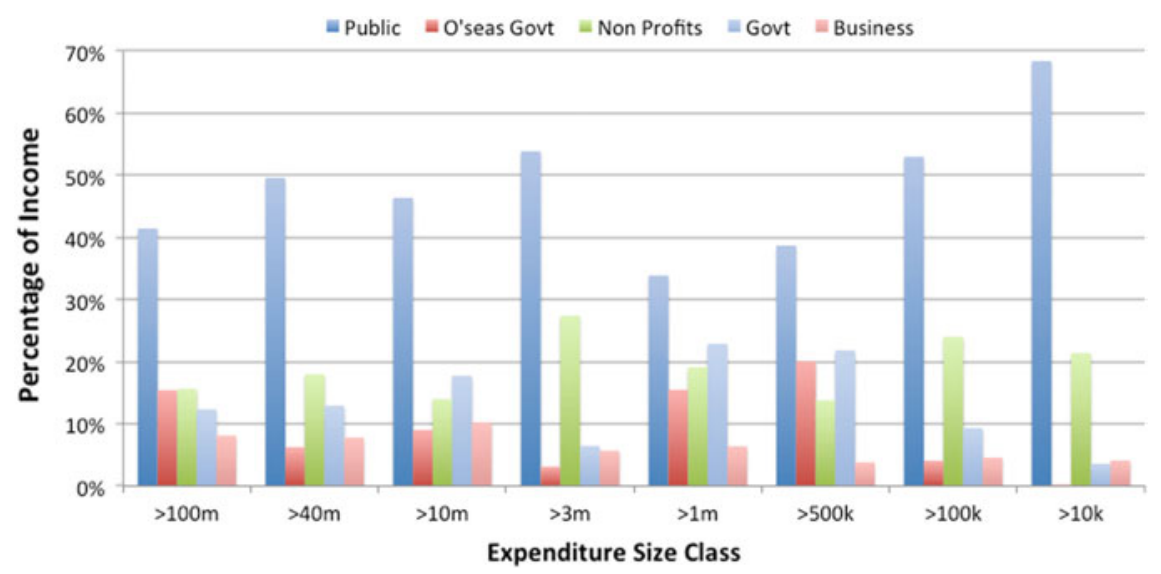

Fig. 31.1 Sources of income for British development NGOs (2009-2014) (Source Banks and Brockington 2018)

period. In comparison, the British government provided just 17 per cent (Fig. 31.1). ${ }^{6}$

This is the case for all size classifications of development NGOs. The smallest development NGOs receive almost 70 per cent of their income from public donations and negligible funding direct from the UK government. ${ }^{7}$ Government funding becomes more prominent when NGOs hit the $£ 100,000$ expenditure mark. Here still, however, the government provides less than 10 per cent of income, on average. It is the mid-size categories of NGOs (between $£ 500,000$ and $£ 3$ million) that must be singled out for their higher proportion of government funding as an income source. Both receive more than 20 per cent of their funding from the UK government. In the size class above this (NGOs spending between $£ 3 \mathrm{~m}$ and $£ 10 \mathrm{~m}$ ), funding from other charities becomes a core component of funding, reducing the relative dependence of this group on government funds.

Looking at the structural composition of the sector over time also provides important new insights into trends and pressures within the sector. The research compared the sector's structural composition in 2009 and in 2014, that is, the "share" of the sector's expenditure held by different size classes of development NGOs. Here we see evidence that changes to UK government spending have led to increasing levels of intermediation within the UK's development NGO sector (Banks and Brockington 2018). Despite a huge 45 per cent increase in funds to the sector over this period, structural unevenness across the sector-with only 8 per cent of organisations dominating around 90 per cent of expenditure-has remained remarkably stable (Banks and Brockington 2018). 
This is because, despite the fact that expenditure growth has taken place across all size classes of NGOs, it has been strongest for the largest, allowing them to maintain this dominance (Banks and Brockington 2018). One of the key shifts here has been mentioned above-that government funds have shifted away from the smallest NGOs and rapidly expanded in volume towards the biggest.

Through this sectoral analysis, we can see the importance of applying the concept of intermediation-most commonly investigated within the broader aid chain, with NGOs holding an intermediary position between donors and local counterparts or beneficiaries - to the domestic sector itself (Banks and Brockington 2018). This process introduces new links within the UK aid chain, with money passing through additional UK-based development NGOs before reaching development partners internationally.

As the biggest NGOs have been receiving increasing volumes of government funding, a new pattern of spending it through other British-based charities has emerged. This is evidenced by an increase in funds from "other non-profits" among smaller size classes. The smallest NGOs, for example, have experienced average losses of government funding of 13 per cent across the period above, at the same time as almost doubling their income from other non-profits (Banks and Brockington 2018). Amidst austerity pressures, the benefits of these funding arrangements are clear (Gulrajani 2017). Although ODA levels have increased with the 0.7 per cent commitment written into law, staffing levels and operating budgets have remained under pressure from austerity measures (Evans 2018). Within this context, smaller NGOs are unable to process the volumes of funds that the Department for International Development (DFID) needs to shift.

In broader analyses of intermediation, funding relationships with donorsand the donor priorities that influence the projects that are designed and implemented by NGOs - are seen as problematic because they have the potential to pull NGOs away from the local realities and beneficiaries that they represent. These findings, however, suggest interesting and important new questions to explore, including (i) how this new form of intermediation affects the efficiency of these new sectoral mechanics, and (ii) whether any negative side-effects are generated as a result. For smaller NGOs now receiving funds through other charities, for example, there is little means through which they can build relationships with DFID, nor positive feedback loops through which they can demonstrate the strength of their approaches and potentially secure more funds. It also eliminates the channels through which DFID can learn from new innovations. There are potentially damaging losses to this on both sides (Evans 2018). 


\subsection{CONCLUSIONS}

As we have seen, despite a burgeoning literature on development NGOs globally, there remain striking knowledge gaps and "blind spots" that act as significant barriers to making more informed civil society policies. One of these is a striking lack of research from a sector-wide perspective, with research being dominated by case study approaches rooted in the largest organisations. This means that we know little about the contributions of development NGOs in the broader system of development cooperation. New methodological advances in Britain (Banks and Brockington 2018) and Canada (Davis 2019) highlight the new insights and findings that can be revealed through a more systematic compilation and analysis of NGO data. They also reveal that common concerns theorised in the literature-such as a heavy dependence on government funding constraining NGO independence and shifting their focus away from the grassroots - may not be as big a concern as commonly conceptualised. Both studies reveal a surprisingly small volume of government funds in relation to the overwhelming and increasing levels of support for development NGOs from private individuals. This sector-wide perspective in Britain also illuminates what we can learn about sectoral mechanics, revealing that processes of intermediation - commonly conceptualised globally within the aid chain-are beginning to occur even domestically, before funds reach international partners. Only through this systematic methodology can we begin to trace and understand how changes in funding and finance influence the sector and how it operates. This is a critical first step in understanding the effectiveness of these mechanics and operations.

These new insights and policies have implications for our understanding and progress towards SDG 17 (Partnerships for the goals). New methodological advancements in NGO research that take a systematic, sector-wide approach to understanding the contributions of development NGOs in Britain and Canada can also begin to shed light on the true extent of civil society's contributions towards meeting these goals. In the UK, in particular, this research also highlights the increasing volumes of financial support for development that development NGOs have been able to mobilise from non-state actors in these efforts.

We also highlight another success story, looking at the ways in which conceptually grounded research has influenced government policy for civil society funding in the Netherlands. This radical new policy that promotes the political roles of NGOs moves far beyond the "business as usual" approach of traditional donors and, as such, has important implications for SDG 17. Moving away from managerialist to transformative ideologies and principles has formed the basis of new relationships that offer flexibility, core funding, and a partnership model that goes beyond simply funding. Such an approach is critical if we seek to catalyse a much stronger and more deeply-rooted, transformative value-added role for development NGOs in meeting the global goals. Importantly, this highlights that not only must we focus on progress 
made towards targets and indicators, we must also focus on modalities- how NGO operations are funded and executed, and whether this enables NGOs to be political as well as professional organisations, generating social and political change alongside their admirable impacts on the ground in service delivery. The ways in which international NGOs manage their local partnerships in the countries where they operate is also critical here in terms of building capacity and offering the flexibility and security of funding that enables greater political action.

Often - and understandably - academic research that talks conceptually about NGOs in ways that undermine diversity serves to irritate, rather than engage with, NGO practitioners. I speak from experience here-our work on NGOs and development is brought up by Duncan Green on his widelyread "Poverty and Power" blog every time he has a frustration to be aired about academic research. This does not mean that NGOs and those working for them are not sympathetic to the core concerns this critical work represents; often these parallel discussions are going on behind closed doors, as Kloster's (2018) recent discussion on the dilemmas of "going global" and losing touch with core civil society values richly illustrates. But, as outsiders, drawing upon a broad range of academic sources of evidence in an effort to test core assumptions or build theories, it can perhaps seem far-removed from-or a too simplified version of - the complex realities and challenges that NGOs grapple with on a daily basis. That this rich body of work can feed into radical new policies that enable NGOs to move back to old roots highlights the importance of academics maintaining a radical stance on development NGOs who continue to fight for the genuine development alternatives they seek to offer.

\section{Notes}

1. AidData, for example-a project compiling and analysing data on foreign aiddoes not include NGOs in their database.

2. In fact, it appears that donors have been more proactive here than researchers. Many donors, including DFID and the Dutch Ministry of Foreign Affairs, ensure that all NGOs funded through ODA input their data online with the International Aid Transparency Initiative in an attempt to make NGO expenditures more transparent and accountable. Currently, however, it is not possible to search this data in ways that allow for a more sector-wide perspective, that is, one cannot search for "all British NGOs funded by DFID". Even if this were possible, this would not necessarily include all British NGOs that are independent of government funds.

3. Although beyond the scope of this chapter, the ways in which NGOs report on their contributions to meeting the SDGs and their responsibilities in holding governments to account through Shadow Reports is an interesting issue. See Long (2018) and International Forum of National NGO Platforms (2018), for example. 
4. Of course, this new policy change is best understood within the recent history of broader changes to the Netherland's foreign aid policy and the institutions that drive it. This is beyond the scope of this chapter here, but Schulpen (2016) and Schulpen et al. (2018) give an excellent overview of these changes while analysing their influence on Dutch development NGOs.

5 . There are some excellent exceptions here, as with the analysis of Buthe et al. (2012) on how 40 leading transnational NGOs in the United States allocate their privately collected finances across their countries of operation. The methodological choice for this is clearly defined given the study's scope and objectives, but by excluding government and multilateral funding within these organisations (and given the fact that it studies a sample of some of the largest organisations), this still means that we have a far from complete picture of NGO contributions to development cooperation from this data. Likewise, an earlier study by Koch et al. (2009) analysed the distributional choices of international NGOs operating across several OECD countries. Diversifying the number of countries under study means looking at fewer organisations within them-and consequently, the biggest. There are no insights, as a result, into the activities and decision-making of international NGOs spending less than $€ 10$ million, of which there are many.

6. The legal commitment to spend 0.7 per cent of gross national income on ODA, enshrined in law in 2015 , increases the relative importance of government funding in relation to the sector's overall income, from 17 to around 20 per cent.

7. Recent changes and additions to DFID's civil society portfolio may have influenced this finding, opening up opportunities for smaller NGOs through the Small Charities Fund.

\section{REFERENCES}

Atia, M., \& Herrold, C. E. (2018). Governing through patronage: The rise of NGOs and the fall of civil society in Palestine and Morocco. VOLUNTAS: International Journal of Voluntary and Non-Profit Organizations, 29(5), 1044-1054.

Banks, N., \& Brockington, D. (2018). Mapping the UK's development NGOs: Income, geography and contributions to development (GDI Working Paper 2019-035). Manchester: University of Manchester.

Banks, N., Hulme, D., \& Edwards, M. (2015). NGOs, states and donors revisited: Still too close for comfort? World Development, 66, 707-718.

Brass, J., Longhofer, W., Robinson, R. S., \& Schnable, A. (2018). NGOs and international development: A review of 35 years of scholarship. World Development, 112, 134-149.

Buthe, T., Major, S., \& de Mello e Souza, A. (2012). The politics of private foreign aid: Humanitarian principles, economic development objectives and organizational interests in the allocation of private aid by NGOs. International Organization, 66(4), 571-607.

CARE Netherlands (2017). From participation to influence: Lessons learned from inclusive governance programming in fragile settings (CARE Netherlands Policy Briefing). The Hague: Author. 
DAC (Development Assistance Committee). (2018). Aid for civil society organisations: Statistics based on DAC members' reporting to the Creditor Reporting System Database (CRS), 2015-2016. Paris: Organisation for Economic Co-operation and Development.

Davis, J. M. (2019). Real "non-governmental" aid and poverty: Comparing privately and publicly financed NGOs in Canada. Canadian Journal of Development Studies/Revue Canadienne D'études Du Développement. https://doi.org/10.1080/ 02255189.2019 .1556623$.

Dicklitch, S., \& Lwanga, D. (2003). The politics of being non-political: Human rights organisations and the creation of a positive human rights culture in Uganda. Human Rights Quarterly, 25(2), 482-509.

Drabek, A. G. (1987). Development alternatives: The challenge for NGOs. An overview of the issues. World Development, 15, ix-xv.

Dupuy, K., Ron, J., \& Prakash, A. (2016). Hands off my regime! Governments' restrictions on foreign aid to non-governmental organisations in poor and middleincome countries. World Development, 84, 299-311.

Evans, R. (2018). Whose problems? Whose solutions? The role of for-profit contractors as managers of British development challenge funds (master's thesis). Amsterdam: University of Amsterdam, International Development Studies.

Gulrajani, N. (2017). Bilateral donors and the age of the national interest: What prospects for challenge by development agencies? World Development, 96, 375-389.

Hulme, D., \& Edwards, M. (1997). NGOs, states and donors: Too close for comfort?. London: Palgrave Macmillan.

International Forum of National NGO Platforms. (2018). Guidelines for CSO shadow reports: Monitoring the implementation of Agenda 2030 at the national level. http:// forus-international.org/en/resources/8.

Kamstra, J., \& Schulpen, L. (2015). Worlds apart but much alike: Donor funding and the homogenization of NGOs in Ghana and Indonesia. Studies in Comparative International Development, 50(3), 331-357.

Kareithi, R. N. M., \& Lund, C. (2012). Review of NGO performance research published in academic journals between 1996 and 2008. South African Journal of Science, 108, 36-44.

Kloster, M. O. (2018). Why it hurts: Save the Children Norway and the dilemmas of "going global". Forum for Development Studies, 46(1), 109-130.

Koch, D. J., Nunnekamp, P., \& Thiele, R. (2009). Keeping a low profile: What determines allocation of aid by non-governmental organizations? World Development, $37(5), 902-918$.

Long, G. (2018). How should civil society stakeholders report their contribution to the 2030 Agenda for Sustainable Development? (Technical paper for the Division of Sustainable Development, UN-DESA). https://sustainabledevelopment.un.org/con tent/documents/18445CSOreporting_paper_revisions_4May.pdf.

Marberg, A., Korzilius, H., \& van Kranenburg, H. (2019). What is in a theme? Professionalization in nonprofit and nongovernmental organizations research. Nonprofit Management and Leadership. https://doi.org/10.1002/nml.21355.

Marburg, A., van Kranenburg, H., \& Korzilius, H. (2016). NGOs in the news: The road to taken-for-grantedness. VOLUNTAS: International Journal of Voluntary and Non-Profit Organizations, 27(6), 2734-2763. 
Ministry of Foreign Affairs of the Netherlands. (2017). Dialogue and dissent theory of change 2.0: Supporting civil society's political role. The Hague: Ministry of Foreign Affairs Civil Society Unit.

Mitlin, D., Hickey, S., \& Bebbington, A. (2007). Reclaiming development? NGOs and the challenge of alternatives. World Development, 35(10), 1699-1720.

Schulpen, L. (2016). The NGO funding game: The case of the Netherlands. Cidin: Radboud University.

Schulpen, L., van Kempen, L., \& Elbers, W. (2018). The changing Dutch NGO: Exploring organisational, strategic and financial changes between 2010-2016. Cidin: Radboud University.

Suarez, D., \& Gugerty, M. K. (2016). Funding civil society? Bilateral government support for development NGOs. VOLUNTAS: International Journal of Voluntary and Non-Profit Organizations, 27(6), 2617-2640.

Ulvila, M., \& Hossain, F. (2002). Development NGOs and political participation of the poor in Bangladesh and Nepal. Voluntas: International Journal of Voluntary and Non-Profit Organizations, 13(2), 149-163.

Vakil, A. C. (1997). Confronting the classification problem: Toward a taxonomy of NGOs. World Development, 25(12), 2057-2070.

Van Wessel, M., Schulpen, L., Hilhorst, D., \& Biekart, K. (2017). Mapping the expectations of the Dutch Strategic Partnerships for lobby and advocacy. Wageningen: Wageningen University and Research, Radboud University Nijmegen and Institute of Social Studies, Erasmus University.

Yanguas, P. (2018). Why we lie about aid: Development and the messy politics of change. London: Zed Books.

Open Access This chapter is licensed under the terms of the Creative Commons Attribution 4.0 International License (http://creativecommons.org/licenses/by/4.0/), which permits use, sharing, adaptation, distribution and reproduction in any medium or format, as long as you give appropriate credit to the original author(s) and the source, provide a link to the Creative Commons license and indicate if changes were made.

The images or other third party material in this chapter are included in the chapter's Creative Commons license, unless indicated otherwise in a credit line to the material. If material is not included in the chapter's Creative Commons license and your intended use is not permitted by statutory regulation or exceeds the permitted use, you will need to obtain permission directly from the copyright holder.

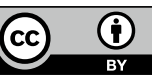

